\title{
Original Anticle
}

\section{Study of Complementary Feeding Practices and Some Related Factors among Mothers Attending Primary Health Centers in Sari, 2013 Year}

\author{
Fatemeh Abdollahi $^{1} \quad$ Jamshid Yazdani Chareti $^{2} \quad *$ Samad Rohani $^{3}$
}

1- Department of Public Health, School of Health, Mazandaran University of Medical Sciences, Sari, Mazandaran, Iran

2- Department of Biostatistics, School of Health, Health Sciences Research Center, Mazandaran University of Medical Sciences, Sari, Iran

3- Department of Public Health, School of Health, Health Sciences Research Center, Mazandaran University of Medical Sciences, Sari, Iran

\author{
*samad.rouhani@gmail.com
}

(Received: 28 Dec 2013; Revised: 15 May 2014; Accepted: 18 Sep 2014)

\section{Abstract}

Background and purpose: Inappropriate complementary feeding practices are one of the causes of malnutrition worldwide. This study was aimed to determine the complementary feeding practices according to World Health Organization recommendation in Sari, Iran.

Materials and Methods: This cross-sectional study on complementary feeding practices assayed the different aspect of infant feeding based on maternal, childbirth, and infant characteristics. This study was conducted during the period between March and June 2013 on 401 mothers of infants under 1 year of age attending primary health centers using Poisson random sampling method and semi-structured questionnaire. A chi-square test was used to analyze the data.

Results: Almost $83.6 \%$ of mothers started complementary feeding at recommended age of 6 months. The most common starting food was Fereni (51.5\%). About half of mothers fed their infants complementary food of appropriate consistency (49\%) with recommended frequency (54.6\%). Fathers' educational level was found to be the significant associated factor with appropriate complementary feeding practices $(\mathrm{P}=0.02)$.

Conclusion: Complementary feeding practices by mothers in the capital city of Mazandaran province are still inappropriate in term of consistency, frequency and type of food introduced. Emphasis should be given to educating mothers and fathers about this important issue.

[AbDollahi F, Yazdani Chareti $J$ *Rohani $S$. Study of Complementary Feeding Practices and Some Related Factors among Mothers Attending Primary Health Centers in Sari, 2013 Year. IJHS 2014; 2(3): 43-48] http://jhs.mazums.ac.ir

Key words: Complementary Feeding, Infant, Mothers Practices 


\section{Introduction}

World Health Organization (WHO) estimated that 9.5 million children under 5 years old died worldwide; of which one-third were due to malnutrition $(1,2)$. In the period of 4-24 months when child moves from breast feed to solid food as its primary source of nutrition is the greater risk of malnutrition (3). Complementary feeding is one of the most important components of infant feeding (4). Insufficient of complementary foods and poor child feeding practice have a significant effect on promotion of optimal growth, health and cognitive development of the child during this important period (5). Thus, the complementary foods should be appropriate, safe, inadequate amount and start timely $(3,4)$. The higher energy intake during this period could result in overfeeding, promoting rapid growth with more central fat (5). WHO survey in 2002 concluded that 6 months are the ideal period for exclusive breastfeeding and after that complementary feeding should be started with continued breast feeding till 2 years (6).

Although breast and formula feeding has been studied extensively, little attention has been paid to complementary feeding. The limited studies are shown considerable variation in complementary feeding practices between countries (5). Pattern of complementary feeding could be affected by socio-economic and cultural factors. As the cereal, and soup, Fereni is the first introduced food for children in Lbanon, India, England and Iran (5, 7-9).

Research in effective interventions and programmatic approaches to improve complementary feeding has been recommended by WHO (10). There is a scarcity of researches on complementary feeding practices and factors associated in Iran specific in Sari as a capital city of Mazandaran. Awareness of these factors will be helpful in planning interventions to get better complementary feeding practices. This is the first report on complementary feeding practices in Sari city to identify the pattern of introduction of foods and demographic, socio- economic and obstetrics factors influencing this practice.

\section{Materials and Methods}

This cross-sectional study is a part of a large study which carried out between March and June 2013 at primary health centers (PHCs) of the capital city of Mazandaran province, Iran involving mothers of infants under 1 year of age using semi-structured questionnaire. According to Statistical Center of Iran (2011), the population of Mazandaran and Sari city is 3,073,943 and 478,370, respectively. Males numbered 238,894 while women numbered 239,476 in Sari. Each household in Mazandaran province has on average 3.7 members while growth rate is $1.02 \%$ (11).

The required sample size in the original study was calculated to be around 401 infants according to the formula for cross-sectional study with $95 \%$ confidence and P-values $0.05 \%$. This study sample was drawn from the total population of 8000 mother-infant who attended PHCs during the period of the study. Stratified random sampling method was used to selection PHCs in five part (north, south, west, east and center) of the city. Eligible mothers who attended to PHCs for infant care were approached using Poisson random sampling method and sampling proportion to the size. Identifying of the first sample was based on the last vaccinated child in the health center, and the reminder was chosen according to the geographic direction until the sampling was completed. The mothers who were not competent to give informed constant had preterm, under-weight and mal-nutrient infant as well mothers who had an infant with congenital abnormality, chronic or severe diseases were excluded from the study. This study was approved by Ethics Medical Committee of Mazandaran University of Medical Sciences.

For a collection of data on sociodemographic characteristics and 
complementary feeding practices a welldesigned questionnaire were used after pretested with 40 unselected mothers (Cronbach's alpha $=0.84)$. Variables related to socio-demographic characteristics were selected based on literature review and included mother and infant's age, gender of infant, height $(\mathrm{cm})$ and weight $(\mathrm{g})$ of infant at time of delivery, level of parent's highest education (lower primary; $\leq 5$, upper primary; 6-11 and completed high school and higher $\geq 12$ ), employment status (home worker, employed), husband's employment status (business, government servants, laborer and other), housing condition (renting and own house) and monthly income (low; <5,999,999 Rials and high; >6,000,000 Rials). Income was categorized into two groups based on monthly income according to Iranian ministry of Finance report based on family income for five people at the data collection period (11). Concerning medical and obstetric related data, the authors asked four questions included gravida, type and place of delivery, and being infant in health road.

Complementary feeding data included; the time and type of introduced complementary feeding (introduce complementary foods at which months of age) (Fereni, soup, rice and other), the type of milk accompany with complementary feeding (breast feeding, formula, cow milk, others) cooking the infant food separately (yes, no), reason for introduced complementary feeding before 6 months (infant diseases, others recommendation, breast feeding complications and others), amount (small amounts of food in frequent time), frequency (2-3 times/day) and consistency (the interval between each new foods) of complementary feeding and adding supplementary such as salt to the food (12).

Data were analyzed using IBM SPSS for Windows (version 20; SPSS Inc., Chicago, IL, USA). The results were presented as proportions. To test the associations between the maternal, childbirth and infant data with complementary feeding practices (the time and type of introduced complementary feeding) chi-square test were done. Statistical significance was taken at $\mathrm{P} \leq 0.05$.

\section{Results}

The mean age of 401 participant mothers and their infants was $27.99 \pm 4.70$ years and $5.74 \pm 3.20$ months, respectively. The majority of mothers (98\%) were healthy, primipara $(71.1 \%)$, home worker $(78.8 \%)$ and their education level was upper primary $(59.3 \%)$. The majority of fathers' educational level was also upper primary $(56.1 \%)$. The mean of household income of the family was 775, $286.78 \pm$ Rialss (1 US Dollar $=3500$ Rialss). The majority of infant was less than 6 months of age $(62 \%)$ and their mean birth height, and weight was $49.59 \pm 1.81 \mathrm{~cm}$ and $3247.08 \pm 434.63 \mathrm{~g}$, respectively. The characteristics of the study group were shown in table 1.

\subsection{One sample missed}

Of all participants, 197 (49.13\%) had introduced complementary feeds. The initial age of introduced complementary feeding was 1 month $(0.5 \%)$ that rose to $5.6 \%$ and $83.6 \%$ by 3 and 6 months respectively. The mean age of introduced complementary food was $5.74 \pm 0.68$ months.

The breastfeeding was the most commonly used milk accompany with complementary feeding $(71.6 \%)$. The most commonly introduced complementary feeding was Fereni (mix of rice, sugar and milk) $(51.5 \%)$. The majority of mothers cooked infant food separately $(51.3 \%)$ and fed their infants in sufficient amount with appropriate frequency $(54.6 \%)$ and appropriate consistency $(49 \%)$.

About 76 mothers (38.6\%) said they added sugar or salt to infant food. The most reason for early introduced complementary feeding was the breast feeding problems $(43.8 \%)$. 
Table 1. Baseline characteristics of study group $(\mathrm{n}=401)$

\begin{tabular}{|c|c|c|}
\hline Variables & Number & Percent (\%) \\
\hline \multicolumn{3}{|l|}{ Age of mother (year) } \\
\hline $16-24$ & 96 & 23.9 \\
\hline $25-36$ & 284 & 70.8 \\
\hline $37 \leq$ & 21 & 5.2 \\
\hline \multicolumn{3}{|l|}{ Husband employed } \\
\hline Business & 202 & 50.4 \\
\hline Government employ & 152 & 37.9 \\
\hline Laborer & 41 & 10.2 \\
\hline Others & 6 & 1.5 \\
\hline \multicolumn{3}{|l|}{ Housing } \\
\hline Renting & 84 & 20.9 \\
\hline Own house & 317 & 79.1 \\
\hline \multicolumn{3}{|l|}{ Type of delivery } \\
\hline Vaginal & 299 & 74.6 \\
\hline Cesarean section & 102 & 25.4 \\
\hline \multicolumn{3}{|l|}{ Place of delivery } \\
\hline Governmental hospital & 211 & 52.6 \\
\hline Private hospital & 190 & 47.4 \\
\hline \multicolumn{3}{|l|}{ Sex of infant } \\
\hline Girl & 210 & 52.4 \\
\hline Boy & 191 & 47.6 \\
\hline \multicolumn{3}{|l|}{ Being in healthy road } \\
\hline No & 5 & 1.2 \\
\hline Yes & 396 & 98.8 \\
\hline \multicolumn{3}{|l|}{ Age of infant (month)* } \\
\hline $1-4$ & 177 & 44.3 \\
\hline $5-6$ & 71 & 17.7 \\
\hline$>6$ & 152 & 38 \\
\hline
\end{tabular}

*Rials (monthly); 1US dollar=35,000 Rials

As shown in table 2, among the maternal, childbirth and infant data, only father educational level was significantly correlated with the complementary feeding practices in the chi-square test. Infants from high educated fathers had a high rate of ideal introduced feeding time than the infant from low educated fathers $(\mathrm{P}=0.02)$.

\section{Discussion}

Feeding pattern and practices during $1^{\text {st }}$ year of life is important issues that should not be ignored by mothers as well health care practitioners. It could affect on the later growth, development and morbidity (13). This study assessed complementary feeding practice among mother-infant pairs from the middle and lower socioeconomic families in sari, Iran based on the WHO recommendation. This study found that more than two third of mothers $(83.6 \%)$ started complementary feeding at ideal age of 6 months which is recommended by WHO. Similar observation was found in studies were done in Nepal $(77.4 \%)$ (4) and other parts of Iran; 70\%, $56.1 \%(8,14)$.

Table 2. Factors associated with complementary feeding practices in chi-square test among mothers-infants attending primary health centers, Sari, 2013

\begin{tabular}{|c|c|c|c|c|c|c|}
\hline \multirow[t]{2}{*}{ Variables } & \multicolumn{2}{|c|}{$\begin{array}{l}\text { Appropriate age of introduced } \\
\text { complementary feeding }\end{array}$} & \multirow{2}{*}{$\begin{array}{c}\text { P- } \\
\text { value }\end{array}$} & \multicolumn{2}{|c|}{$\begin{array}{c}\text { Appropriate type of introduced } \\
\text { complementary feeding }\end{array}$} & \multirow{2}{*}{$\begin{array}{l}\text { P- } \\
\text { value }\end{array}$} \\
\hline & $\leq 6$ months & $>6$ months & & Fereni & Others & \\
\hline \multicolumn{7}{|l|}{ Age of mother (year) } \\
\hline $16-24$ & $6(12.8)$ & $41(87.2)$ & 0.40 & $22(45.8)$ & $26(54.2)$ & \\
\hline $25-36$ & $23(16.7)$ & $115(83.3)$ & & $72(52.2$ & $66(47.8)$ & 0.36 \\
\hline$>36$ & $3(30)$ & $7(70)$ & & 7 (70) & $3(30)$ & \\
\hline \multicolumn{7}{|l|}{ Education } \\
\hline Lower primary $(\leq 5)$ & $3(33.3)$ & $6(66.7)$ & 0.26 & $5(44.4)$ & $6(55.6)$ & \\
\hline Upper primary $(6-1)$ & $14(13.6)$ & $89(86.4)$ & & $48(46.2)$ & $54(53.8)$ & 0.19 \\
\hline Completed high school and higher $(\geq 12)$ & $15(18.1)$ & $68(81.9)$ & & $49(59)$ & $34(41)$ & \\
\hline \multicolumn{7}{|l|}{ Employed } \\
\hline Home worker & $23(14.6)$ & $134(85.4)$ & 0.13 & $82(52.2)$ & $75(47.8)$ & \\
\hline Employed & $9(23.7)$ & $29(76.3)$ & & $19(48.7$ & $20(51.3)$ & 0.41 \\
\hline \multicolumn{7}{|l|}{ Husband education (years) } \\
\hline Lower primary $(\leq 5)$ & $4(44.4)$ & $5(55.6)$ & 0.02 & $6(66.7)$ & $5(33.3)$ & \\
\hline Upper primary (6-11) & $14(12.3)$ & $100(87.7)$ & & $54(47.4)$ & $58(52.6)$ & 0.32 \\
\hline Completed high school and higher $(\geq 12)$ & $14(19.4)$ & $58(80.6)$ & & $41(56.2)$ & $32(43.8)$ & \\
\hline \multicolumn{7}{|l|}{ Total household income (Rialss/month)* } \\
\hline $5,999,999 \geq$ Low & $5(13.5)$ & $32(86.5)$ & 0.40 & $21(56.8)$ & $16(43.2)$ & \\
\hline $6,000,000 \geq$ High & $27(17.1)$ & $131(82.9)$ & & $80(50.3)$ & $79(49.7)$ & 0.30 \\
\hline \multicolumn{7}{|l|}{ Gravida } \\
\hline Primiparous & $22(15.6)$ & $119(84.4)$ & 0.38 & $73(51.8)$ & $68(48.2)$ & \\
\hline Multipara & $10(18.5)$ & $44(81.5)$ & & $28(50.9)$ & $27(49.1)$ & 0.52 \\
\hline \multicolumn{7}{|l|}{ Sex of infant } \\
\hline Girl & $16(16)$ & $84(84)$ & 0.51 & $56(56)$ & $44(44)$ & 0.12 \\
\hline Boy & $16(16.8)$ & $79(83.2)$ & & 45 (46.9) & $51(53.1)$ & 0.12 \\
\hline
\end{tabular}

*Rials (monthly); 1 US dollar=35,000 Rials 
Only $32(16.4 \%)$ mothers in this study initiated complementary feeding soon before 6 months. This finding is much less compared with the report by Batal et al., in Lebanon that found only $11.9 \%$ of mothers practiced complementary feeding at appropriate time (7). This difference might be due to variations in the population with different cultures under study. Although most infants in this study were not introduced to complementary feeding too early, but health care provider and also mothers should be aware of signs that infant is ready for complementary feeding, rather than state that the infant must start solid foods at the 4-months or 6-months and also assure the mother that her infant can acquire adequate nutrition from breast feeding alone until 6-month of age.

This study showed that the most common starting food was Fereni (51.5\%). Rice has been a principle complementary feeding in other parts of Iran (9) and Middle East countries such as Iraq (15). Still, about half of mothers in this study were not giving feeds in the appropriate type similar to findings of the study by Batal et al., in Lebanon that indicates to need to interventions $(7,14)$.

Regarding the consistency and frequency of complementary feeding, this study found that about half of mothers fed the food of appropriate consistency and in sufficient amount with appropriate frequency as per WHO recommendation, which stated that infants should be given complementary food 2-3 times/day in addition to breastfeeding (10). Similar finding to this study was found in the Nepalese study by Chapagain (16) However, this finding is much less compared with the report by Torabi et al. in Jahrom (9) and much more in comparison with the other Nepali study by Subba and colleagues (4). This variation might be because of different population with different cultures under study. As geographic difference are important to determine the access to food and food distribution (3).
This study did not find any statistically significant association of maternal, childbirth and infant characteristics with appropriate feeding practice except for fathers' education status. In agreement with Khanal and colleagues' study, father' educational level was found to be protective against inappropriate feeding practices. Educated mothers and fathers are more likely to get better education message and may be in higher socioeconomic situation which could positively result to infant feeding practices (3).

The study finding indicated that there is still a gap between ideal patterns of complementary feeding practice in Sari with the WHO recommendation. This finding highlights the importance of providing feeding advice during prenatal visits to improve the suitable feeding practices. The study finding that fathers' education was providing better infant feeding has an important public health implication. It is reasonable for health workers to educate mothers and fathers by counseling and provide skills to better infant feeding practices.

This study strength is using validated questionnaire and methodology with high responses rate. However, this observational study limits to developing causal inference. As the data were based on interviews and retrospective information, recall bias may also occur.

\section{Acknowledgement}

This study was supported by grant from MAZUMS. Authors are grateful to all participants who made this study possible.

\section{References}

1. World Health Organization. Infant and young child feeding: Model chapter for textbooks for medical students and allied health professionals. Geneva, Switzerland: WHO; 2009.

2. Black RE, Cousens S, Johnson H, Lawn JE, Rudan I, G Bassani DG, et al. Global, 
regional, and national causes of child mortality in 2008: a systematic analysis. The Lancet 2010; 375(9730): 1969-87.

3. Khanal V, Sauer K, Zhao Y. Determinants of complementary feeding practices among Nepalese children aged 6-23 months: findings from Demographic and Health Survey 2011. BMC Pediatr 2013; 13: 131.

4. Subba SH, Chandrashekhar TS, Binu VS, Joshi HS, Rana MS, Dixit SB. Infant feeding practices of mothers in an urban area in Nepal. Kathmandu Univ Med J (KUMJ) 2007; 5(1): 42-7.

5. Kuriyan R, Kurpad AV. Complementary feeding patterns in India. Nutr Metab Cardiovasc Dis 2012; 22(10): 799-805.

6. Kramer MS, Kakuma R. The optimal duration of exclusive breastfeeding: a systematic review. Adv Exp Med Biol 2004; 554: 63-77.

7. Batal $\mathrm{M}$, Boulghourjian $\mathrm{C}$, Akik C. Complementary feeding patterns in a developing country: a cross-sectional study across Lebanon. East Mediterr Health J 2010; 16(2): 180-6.

8. Imani M, Mohamadi M. Pattern of complementary feeding practice and associated factors in urban and rural area of Zabol. Proceedings of the $3^{\text {rd }}$ National Conference and the $2^{\text {nd }}$ International Conference on Skill Training and Employment; 2014 May 7; Tehran, Iran.

9. Torabi S, Monagheb A, Rahmanian S, Zahedi R, Solh Joo Z. Nutritional status and factors associated among children under two years in Jahrom Proceedings of the $3^{\text {rd }}$ National Conference and the $2^{\text {nd }}$ International Conference on Skill Training and Employment; 2014 May 7; Tehran, Iran.

10. World Health Organization. Global strategy for infant and young child feeding. Geneva, Switzerland: WHO; 2003.

11. Statistical Center of Iran. Census of Population and Housing 2011 [Online]. [cited 2012 Dec 20]; Available from: URL: http://www.amar.org.ir/Portals/0/Files/abstract /1390/n_sarshomari90_2.pdf. [In Persian]

12. Dewey K. Guiding principles for complementary feeding of the breastfed child. Geneva, Switzerland: WHO; 2003.

13. Wright AL, Holberg C, Taussig LM. Infantfeeding practices among middle-class Anglos and Hispanics. Pediatrics 1988; $82(3 \mathrm{Pt} \mathrm{2})$ : 496-503.

14. Fesharakinia A, Sharifzadeh Gh, Habbiby M. Evaluation of infants' complementary nutrition pattern and some of its associated factors in Birjand. J Birjand Univ Med Sci 2009; 16(3): 40-6. [In Persian]

15. Abdulla SM. Food habits in Iraq [MSc Thesis]. Alexandria, Egypt; High Institute of Public Health, University of Alexandria; 1979.

16. Chapagain RH. Factors affecting complementary feeding practices of Nepali mothers for 6 months to 24 months children. J Nepal Health Res Counc 2013; 11(24): 205-7. 